NBER WORKING PAPER SERIES

\title{
SIBLING SIMILARITY AND DIFFERENCE IN SOCIOECONOMIC STATUS: \\ LIFE COURSE AND FAMILY RESOURCE EFFECTS
}

\author{
Dalton Conley \\ Rebecca Glauber \\ Working Paper 11320 \\ http://www.nber.org/papers/w11320 \\ NATIONAL BUREAU OF ECONOMIC RESEARCH \\ 1050 Massachusetts Avenue \\ Cambridge, MA 02138 \\ May 2005
}

The authors would like to thank Bruce Western and the participants of the Summer Research Workshop of the Institute for Research on Poverty at the University of Wisconsin-Madison for their helpful comments and suggestions. Any opinions expressed are those of the authors alone.The views expressed herein are those of the author(s) and do not necessarily reflect the views of the National Bureau of Economic Research.

(C2005 by Dalton Conley and Rebecca Glauber. All rights reserved. Short sections of text, not to exceed two paragraphs, may be quoted without explicit permission provided that full credit, including $\odot$ notice, is given to the source. 
Sibling Similarity and Difference in Socioeconomic Status: Life Course and Family Resource Effects Dalton Conley and Rebecca Glauber

NBER Working Paper No. 11320

May 2005

JEL No. J0

\begin{abstract}
$\underline{\text { ABSTRACT }}$
For decades, geneticists and social scientists have relied on sibling correlations as indicative of the effects of genes and environment on behavioral traits and socioeconomic outcomes. The current paper advances this line of inquiry by exploring sibling similarity across a variety of socioeconomic outcomes and by providing answers to two relatively under-examined questions: do siblings", socioeconomic statuses diverge or converge across the life course? And do siblings from demographic groups that putatively differ on the degree of opportunity they enjoy vary with respect to how similar they turn out? Findings inform theoretical debates over parental investment models, especially in relation to diverging opportunities and capital constraints, and life course status attainment models. We report three new findings. First, sibling resemblance in occupational prestige is explained almost entirely by shared education, and sibling resemblance in family income is explained almost entirely by the combination of shared education, occupational prestige, and earnings. This is contrasted to sibling resemblance in earnings and wealth, as siblings retain 60 percent of their resemblance in earnings once we control for education and occupational prestige, and siblings retain more than 30 percent of their resemblance in wealth once we control for all other socioeconomic outcomes. Second, across the life course, siblings converge in earnings and income and maintain stable correlations in education, occupational prestige, and wealth. Third, black siblings have significantly lower correlations on earnings and income than nonblack siblings overall, but black siblings dramatically converge in income across the life course - in their twenties black siblings have a .181 correlation in income and above age 40 they have a .826 correlation in income - suggesting almost complete social reproduction in income by the fifth decade of life for African Americans. This pattern does not hold for nonblack siblings. Furthermore, when we split the sample by class and age, we find the opposite effect: by age 40 and above, siblings from higher SES families tend to increase in their resemblance while those from lower SES families do not. Descriptive accounts about the openness of American society, then, strongly depend on which group we are talking about and at which stage in the life course we measure economic status.

Dalton Conley

Department of Sociology

New York University

269 Mercer Street, 4th Floor

New York, NY 10003

and NBER

dc66@nyu.edu

Rebecca Glauber

New York University

rkg214@nyu.edu
\end{abstract}




\section{Sibling Similarity and Difference in Socioeconomic Status: Life Course and Family Resource Effects}

How similar are the socioeconomic statuses of siblings? The current study attempts to document the degree of sibling resemblance in a number of components of socioeconomic status. It also aims to determine when siblings most resemble each other and which siblings resemble each other to the greatest degree. For nearly a century behavioral geneticists have used sibling correlations as measures of the effects of genes and shared environment on behavioral traits (McGue and Bouchard 1998), and for more than three decades economists and sociologists have used sibling correlations as "omnibus measures" (Solon, Page, Duncan 2000: 383) of the effects of family and community on socioeconomic outcomes (Hauser, Sheridan, Warren 1999; Jencks 1972; Solon et al. 1991). Despite this research tradition, two questions remain relatively unexplored: do siblings' socioeconomic statuses diverge or converge across the life course? And do siblings from demographic groups that putatively differ on the degree of opportunity they enjoy vary with respect to how similar they turn out? Each of these empirical questions has important theoretical implications. The question about the waxing and waning of sibling associations over the life course has important implications for economic models of parental investment in offspring as well as for life course theories of status attainment. Subgroup variation in the strength of sibling associations informs us about potentially divergent investment strategies among families who face differing capital constraints and opportunity structures.

This relationship of family background to the outcomes of offspring is one of the most central concerns of human capital and stratification research. Yet, as Hauser and Sewell have stated, "Nowhere has a research agenda of such substantive importance had to survive on such meager scraps of data" (1976: quoted in Solon et al. 1991: 512). It is not just data that have been 
lacking. As Becker and Tomes (1986) write, "while sociologists have taken the lead in estimating the impact of family background on a number of outcomes-most notably educational and occupational attainment—-they have lacked a clear explication of an underlying behavioral model." The current paper tries to address both of these concerns with new data as well as by engaging with economic models of the family.

With respect to data, the current analysis represents a marked improvement over previous work. Here, we analyze data from the 1983 to 2001 waves of the Panel Study of Income Dynamics (PSID), a resource that provides a number of cases that dwarfs those used in previous sibling research (on income, at least). These waves of the PSID also provide data on individuals that are substantially older than those used by previous researchers (and who therefore may have much more stable earnings profiles). The PSID allows the examination of a number of outcomes all in one data set: education, occupation, earnings, income, and wealth, which has been notably absent from previous studies. Analyses of sibling correlations across the life course and across demographic groups also address theoretical concern over parental investment behavior (Becker and Tomes 1976, 1979; Behrman, Pollak and Taubman 1982, 1989), over life course and status attainment sequencing models, and over the relative intractability of environmental and genetic family background factors and inter-sibling effects.

\section{PREVIOUS WORK ON SIBLING RESEMBLANCE}

There is a long tradition of stratification and social mobility research that deploys fatherson correlations in socioeconomic outcomes (for a thorough review, see Conley, Glauber, Olasky 2004). Father-son correlations (also known as IGE - intergenerational earnings elasticities) were questionable measures of social mobility three decades ago (for debate over this, see: Acker [1973] and Goldthorpe [1983]), and are even less adequate today given contemporary family 
fluidity (see, for example, Cherlin 1992; Furstenberg and Cherlin 1991; Gerson 1993) and women's increased educational and labor market statuses. As others before us, we argue instead for the use of sibling correlations as summative estimates of the combined effects of shared environmental factors, shared genetic factors, and inter-sibling effects on socioeconomic outcomes. Whereas most social science research articulates the use of sibling correlations to account for measurable and un-measurable family background factors (Warren, Sheridan, and Hauser 2002), or as “omnibus measures” of family and community factors (Corcoran et al. 1990; Markus et al. 2002; Solon et al. 1991; Teachman 1995; Teachman, Carver, and Day 1995), we acknowledge that sibling correlations may also capture shared genetic traits and inter-sibling effects.

There are limits on what we can infer from such correlations, and these should be mentioned up front. Specifically, once we open up the possibility of within-family heterogeneity in parental investment, take into account shared genetic factors, and siblings' potential effects on each other, sibling correlations cannot accurately represent causal processes related to the impact of family background.

That is, while it is trivially true that if there is a zero correlation between siblings (or between parent and child), family background can be said to have no net impact, this is a descriptive account only. For example, it could be the case that family background matters enormously, but that within-family dynamics obscure this fact in sibling or parent-child associations of socioeconomic status. ${ }^{1}$ For example, envision the case of a two-child family in which the elder child is expected to sacrifice for the benefit of the younger sibling. If such a (1994).

\footnotetext{
${ }^{1}$ For a good example of how these processes can be modeled, see Behrman, Rosenzweig, and Taubman
} 
dynamic were widespread in a given society and resulted in downward mobility for the sacrificing sibling and upward mobility for the sibling who benefited from the sacrifice, we could actually observe a negative sibling correlation and a zero parent-child correlation (since the upwardly mobile offspring would be cancelled out by the downwardly mobile offspring in a random sample of parents and children).

If such dynamics were systematically stratified by a measurable variable such as gender or birth position, then we could accurately describe the intra-family dynamics by observing correlations across within-family subgroups such as latter-borns or boys. But if the way that families generated outcomes among children was based on some unobservable factor-such as parental belief in child ability - then to the researcher, the apparent result may be randomness and a potentially faulty observation that family background means little. In fact, what it would mean is that the family was acting as a primary queuing mechanism for socioeconomic opportunity.

Given the apparent difficulty in modeling the true impact of family background, in light of shared environmental and genetic traits and inter-sibling effects, what are we to make of sibling correlations? The answer is that we can read a sibling correlation as a global effect of family background —environmental and genetic factors— if we assume a model in which offspring are invested in equally (or at least that any favoritism is randomly distributed) and in which siblings have only a mean-regressive effect on each other. That is, that they tend to cause each other to be more alike than they would in each other's absence. This is not an entirely unreasonable assumption, but it is an assumption nonetheless.

Research in the tradition of behavioral genetics attempts to parcel out genetic and environmental components of the effect of family background on social outcomes using twin and 
other kin comparisons. A host of outcomes have been examined in this context, ranging from cognitive ability (Plomin 1988) to mental health (Gottesman and Shields 1982; Kendler and Robinette 1983; Reich et al. 1987) to behavioral outcomes such as delinquent behavior (Rowe 1983 ) to the socio-economic (Behrman, Hrubec, Taubman and Wales 1980; Behrman, Pollack and Taubman 1995). (For a general review of this research methodology, see Plomin [1986], Plomin and Daniels [1988]) or Plomin, DeFries and Loehlin [1989].) However, these studies have been criticized for not taking account of differences in the genetic-environmental covariance among different kin and the degree of assortative mating in the population (see, Goldberger 1977, 1979). And these studies have been criticized for attempting to disentangle environmental from genetic factors, when such a procedure may not be wholly possible (Feldman and Lewotin 1975; Layzer 1974). We share these concerns, and therefore, we do not attempt to unravel the knot of common genes and environment but rather, we view correlations as descriptive of shared environment, shared genetic factors, and inter-sibling effects.

Studies of sibling resemblance on occupational and educational status find that these factors explain about half of the variance in schooling and a third of the variance in occupational status (Hauser and Mossel 1985; Hauser and Sewell 1986; Jencks et al. 1979). Sibling resemblances also vary depending on parity and sex, with older brothers and younger brothers having the highest correlations (Benin and Johnson 1984) and older sisters and younger brothers having the lowest correlations (Hauser and Wong 1989). More recently, sociologists and economists have begun to examine sibling correlations on strictly economic outcomes, such as earnings. Solon et al. (1991) use longitudinal data from the PSID and estimate correlations of .448 for men's permanent earnings, .342 for men's family income, and .276 for women's family income. 
Their findings suggest that earlier studies may have underestimated the effect of family background on income variables by using single-year income data. Mazumder and Levine (2003), use data from the 1966 and 1979 National Longitudinal Surveys, ${ }^{2}$ and find a significant increase in brothers' earnings correlations, but no significant increase in brothers' education correlations. Finally, one recent paper addresses wealth, in contrast to income (Charles and Hurst 2003). However, the authors examine age-adjusted parent-child correlations, not sibling correlations. In this respect, their analysis answers a slightly different question from that addressed in the current study with respect to wealth. Parent-child correlations may be affected by the change in the distribution of wealth and family types across cohorts to a much greater extent than are sibling correlations. Wealth is also more unequally distributed than income, especially across racial groups (for example, Conley 1999; Keister 2000; Oliver and Shapiro 1995), and by not taking wealth into account, previous studies have missed a significant amount of variation in families' level of economic resources and inequality between families.

The current study makes several important contributions to the literature, specifically by examining wealth in addition to income and earnings, by utilizing the most recent waves of PSID data, and most importantly, by examining population subgroup and life course differences. Previous studies have been limited in their explanatory power due in part to their tendency to use all-male, young, and/or localized samples (for example, The Wisconsin Longitudinal Study [WLS]; Kalamazoo; and Lincoln, Nebraska). The current study benefits from its use of the PSID,

\footnotetext{
${ }^{2}$ They advocate in favor of the NLS and against the PSID because "the NLS datasets allow us to construct large samples of siblings that are nationally representative in each time period and are less susceptible to sample attrition." However, in contrast to the NLS, the PSID provides better data on wealth.
} 
in that it both allows for the inclusion of sisters and avoids the limitations inherent in a sample that is not nationally representative or includes only young adults.

\section{THEORETICAL ARGUMENTS ABOUT SIBLING RESEMBLANCE AND EXPECTED} TRENDS

We are primarily interested in life course and resource group effects on sibling

resemblances. However, we turn first to a comparison of sibling resemblances across various socioeconomic outcome measures, and importantly, to an analysis of resemblances on each outcome while controlling for putatively earlier-life outcomes. This initial analysis is important for two reasons. First, it expands upon previous research by Warren et al. (2002) and Hauser et al. (1999) examining the extent to which sibling resemblances on some outcomes are part and parcel of their similarity on other outcomes. The authors explore occupational and educational attainment, and we add to this earnings, income, and wealth. Second, and perhaps more importantly, we note that sibling correlations are summative measures of three inter-related factors-shared environment, shared genetic endowments, and inter-sibling effects. Exploring occupational prestige net of education, earnings net of occupational prestige and education, income net of earnings, occupational prestige, and education, and wealth net of all four other socioeconomic outcome measures provides some purchase on when shared environment (especially parental investment behavior), shared genetic endowments, and inter-sibling effects matter more than others.

Parental preference models lead us to expect differences in raw correlations across socioeconomic outcome measures as well as differences in correlations controlling for other socioeconomic outcomes. Becker and Tomes (1976) hold that parents either have child-neutral preferences whereby they invest equally in both children, or they have child-equality preferences whereby they invest differentially in children to equalize their ultimate status attainment. In the 
former, parents follow an "efficiency" model. Since the returns to investing in a child with greater innate endowments are greater than those that result from marginal investment in a less well endowed child, parents may reinforce inequality. In the latter paradigm, parents follow a "wealth" model and invest more in the human capital of their endowed child and make compensatory investments in the non-human capital (that is, wealth and income) of their less endowed child.

Alternatively, parents may be less concerned with equalizing the wealth of their children and more concerned with equalizing the earnings of their children. In a series of studies on parental preference models, Behrman et al. $(1982,1989)$ elaborate a "separable earningsbequest" model as an alternative to Becker and Tomes' wealth model. Whereas in the wealth model parents are concerned with the combination of earnings and wealth of their children as indicative of their ultimate well-being, in the separable earnings-bequest model, parents view earnings and wealth as separate factors - and parents attempt to maximize earnings over total income or wealth, since earnings are valued more than unearned income. Their analysis of fraternal white male twins shows that parents transfer wealth to their children equally, but transfer resources to their children unequally so as to increase the earnings of their less endowed child.

Given Becker and Tomes' wealth model, we would expect less sibling resemblance in education and more sibling resemblance in income and wealth. Given Behrman et al.'s separable earnings-bequest model, we would expect positive sibling correlations in earnings, and to a 
lesser extent, in earnings related outcomes such as total income and wealth. ${ }^{3}$ Taken together, parental preference models also lead us to expect significant sibling correlations in some socioeconomic outcome measures net of other measures. The theories diverge with respect to earnings and wealth, where Becker and Tomes' theory would lead us to predict lower earnings correlations once we control for education and occupational prestige and wealth correlations that remain relatively substantial once we control for all other socioeconomic outcome measures. Behrman et al.'s $(1982,1989)$ theory would lead us to predict earnings correlations that remain relatively strong once we control for education, occupational prestige, earnings, and income. The addition of wealth to the empirical analysis is important for these concerns since it is wealth that is most easily affected by parents because it is sensitive to bequests and direct transfers more than earnings or income. In other words, it may be much more realistic for parents to equalize net worth levels than income streams (and certainly than earnings).

Of course, sibling correlations are most likely due to a combination of factors and not only to parental investment behavior. Residual correlations in occupational prestige net of education might be due to inter-sibling effects (such as job referrals) or the shared experience of labor market discrimination, parental investment decisions to maximize siblings' occupational attainment outside of the traditional educational investment route, or shared genetic endowments that structure occupational attainment more than educational attainment. Significant residual sibling correlations in earnings net of educational attainment and occupational prestige might be due to parental investment strategies to maximize earnings, or to measurement error present in

\footnotetext{
${ }^{3}$ Both sets of theories, Becker and Tomes' and Behrman et al.'s, consider parental preference models under varying levels of family resources given varying capital market imperfections (differing capital structures based on taxes, investment opportunities, and transaction costs). The PSID does not afford us the ability to compare these varying levels of capital market imperfections.
} 
education and occupation and not in earnings, or to inter-sibling effects. Net of labor market earnings, family income is primarily comprised of investment behavior, marriage market effects, and governmental and parental transfers. Significant residual correlations in income net of earnings, occupational prestige, and education may be due to marriage market effects firstly, and to a lesser degree similarity in sources of unearned household income-welfare, return on investments and, of course, private (parental) transfers. Thus, while our findings may speak to parental investment models, we cannot rule out the role of sibling similarity in other areas.

\section{Sibling Resemblance over the Life Course}

Our second question of interest regards sibling correlations across the life course, namely, what is the patterning of sibling convergence or divergence across the life course for different socioeconomic outcomes? Here we rely on parental investment models as well as life course status attainment models to formulate expectations regarding correlations in various outcome measures across the life course. The parental investment models of Becker and Tomes (1976) and Behrman et al. $(1982,1989)$ lead us to expect that siblings' social statuses "converge" across the life course. That is, there are multiple routes to economic success and it is the downstream economic measures (the ultimate rewards) that are maximized by parents. While Becker and Tomes and Behrman et al. differ in respect to which outcome they emphasize (wealth versus earnings and income), both lead us to expect sibling convergence in non-human capital outcomes. Given these models, we would also expect less convergence among education and occupational prestige (since they may be set and stabilize relatively early in adulthood). These models lead us to hypothesize: 
$\mathrm{H} 1_{0}$ : sibling correlations for earnings, income, and wealth for less than 25 years of age $<$ correlations on these measures for 35 years of age $<$ correlations on these measures for 45 years of age.

Alternatively, it might be the case that the patterning of life events is such that siblings diverge in later stages of the life cycle, especially on non-human capital outcomes. This might hold true if parents (and inter-sibling) influences are primarily made when offspring are children at home, and decline in importance as children reach adulthood - as peer effects trump family effects. Furthermore, sociological life course models hold that life patterns and the sequencing of social roles are structured by duration and order (Elder 1985; Rindfuss, Swicegood, and Rosenfeld 1987). Analyses of stratification across the life course tend to focus either on macrolevel state effects (Mayer and Schoepflin 1989), or on micro-level social background effects. This latter set of status attainment studies argues that earlier statuses structure later statuses-that is, parents' statuses affect children's educational attainment which then affects their occupational attainment and later-life earnings (Blau and Duncan 1967; Featherman and Hauser 1978). This sequencing implies that as individuals age, earlier-life statuses become less directly—and more indirectly—indicative of later-life statuses. In support of these theoretical models, research has found that the effect of family background on occupational attainment declines with age (Blau and Duncan 1967; Featherman and Hauser 1978; Hauser et al. 1999; Warren 2001; Warren et al. 2002). In addition to the expected and "orderly" decline of educational attainment and family background factors across the life course, research by Jencks (1972) suggests that income is affected by many chance life events, or "luck." Following these theories, we would expect higher sibling correlations across all measures, but especially in earnings and income, at earlier stages in the life course. Following these models, we provide the alternative hypothesis: 
$\mathrm{H} 1_{\mathrm{a}}$ : sibling correlations for earnings and income less than 25 years of age $>$ correlations for 35 years of age > correlations for 45 years of age.

While a handful of recent studies have examined cohort trends in father-son income elasticities (Levine and Mazumder 2002; Mayer and Lopoo 2005), or cohort trends in father-son occupational mobility (Biblarz, Bengslan, and Bucar 1996; Grusky and DiPrete 1990; Hout 1988), few studies have examined age trends in sibling similarities. Warren et al.'s (2002) analysis comes closest to our study in that they use longitudinal data from the WLS and find that siblings become less occupationally similar as they age. Their findings, however, are subject to limitations of a nearly all-white, localized sample. We exploit the PSID longitudinal design and test these competing hypotheses.

\section{Sibling Resemblance across Population Subgroups}

This paper also makes a contribution by examining differences in the strength of sibling resemblance among various subgroups in the population. We split the sample by race and maternal education (as a proxy for parental economic resources). There is a theoretical logic guiding the choice of these dimensions along which to cleave our data. Becker and Tomes (1979) argue that the rates of return to parental investments differ across type of investment such that investments in human capital are initially more profitable. Poorer families are more likely to invest only in the human capital of children. Becker and Tomes (1986) posit that with capital constraints, resource-constrained parents may not be able to optimally invest in their children's human capital. Such underinvestment may lead to higher degrees of sibling resemblance at lower incomes since "high ability children from poor families may receive the same low level of education as a sibling with lower academic ability, compressing their earnings compared with 
similarly different siblings from a prosperous family" (Mazumder and Levine 2003: 16). ${ }^{4}$

Behrman and Taubman (1990) find some support for Becker and Tomes' (1986) hypothesis in

that parent-child income elasticities for whites are lower than for nonwhites. However, when

they include a squared parent's income term, findings do not lend support to Becker and Tomes'

hypothesis.

Following this capital constraint model (which, like the parental preference model

assumes either equal investment or equal outcome norms among parents), we hypothesize:

$\mathrm{H} 2_{0}$ : sibling correlations among groups with fewer relative resources (black families, children of parents with lower educational attainment, and large families) > correlations among groups with greater relative resources (nonblack families, children of parents with higher educational attainment, and small families).

The alternative hypothesis to Becker and Tomes' (1986) theory is that among families

that are disadvantaged, we should observe greater sibling disparities (that is, lower correlations).

Previous qualitative work (Conley 2004) suggests that among disadvantaged households, sibling

disparities tend to increase, since limited opportunities and resources may elicit parenting

strategies that accentuate sibling differences by directing family resources to the better-endowed

sibling(s) for whom upward mobility is most likely. This research also suggests that among

\footnotetext{
${ }^{4}$ Indeed, this is what Mazumder and Levine find: lower correlations among high-income siblings in both the 1968 and 1979 waves of the PSID. However, when they split the sample along the median, they end up with only a maximum of 185 multiple sibling sets in an income group (in the 1979 wave of the PSID, they have 1,086 cases from 901 families in all). Even if these were all two-sibling sets, then the maximum number of pairs for each income group would be 92-quite a small number. If siblings' mean outcome is entirely related to their background characteristics, then splitting on the mean should produce the same results as splitting on all background measures. However, such a small sample size introduces random error and further, the assumption is untestable given that many family background characteristics are unobservable. Even more important, however, is the fact that they do not split the sample based on the parental characteristics - as would be appropriate for the Becker-Tomes model— but rather by the incomes of the adult siblings themselves. This makes the sample split endogenous to their outcomes. In other words, what they may be observing could be a result of sibling decisions regarding tradeoffs between equity and efficiency. If certain sibships value equality, they may sacrifice the attainment of the betterendowed sibling, bringing the overall mean down, but resulting in a higher correlation between siblings. By contrast, we split the sample by parental measures, which are at least temporally anterior to the sibling outcomes.
} 
families that are well-endowed with class resources (and are racially privileged as well), parents often invest more heavily in those offspring they see as having the worst chances for success in the education system and/or labor market—in a compensatory fashion as the "separable earnings-bequest" model (Behrman et al. 1989) or the "child equality" model of Becker and Tomes would predict. Following these models, we posit an alternative hypothesis:

$\mathrm{H} 2 \mathrm{a}$ : sibling correlations among groups with fewer relative resources $<$ correlations among groups with greater relative resources. This difference in correlations should be most distinct for education, occupational prestige, and earnings, and less pronounced for total income and wealth.

We might expect this outcome for other reasons as well, namely, if the "price effect" of human capital investment trumps the "preference displacement effect." The preference displacement effect suggests that the budget constraint moves the earnings (and educational) possibility frontier closer to the origin, resulting in greater similarity among the offspring (similar to Becker and Tomes' model) since parents have minimal levels of investment that they desire to maintain among all children. In contrast to this effect, the price effect suggests that when parents are budget constrained—by virtue of low income and wealth or larger family size—-students are more likely to be eligible for financial assistance, which itself may vary with children's endowments (see, Behrman et al. 1989). In other words, relying on outside financing accentuates endowment heterogeneity. This is really a public finance model of the "strategic investment" model at the family level.

As was the case in the previous section, the addition of wealth is important for these analyses since it is wealth that is most sensitive to parental bequests and direct transfers, and therefore the measure which may reflect the most "compensatory" behavior on the part of parents (or siblings). Likewise, wealth levels may capture the effects of borrowing on the part of 
offspring to self-finance human capital acquisition. Namely, highly endowed students may receive more aid and thus complete schooling with less debt than those less-endowed students who are forced to borrow to finance their higher education (Behrman et al. 1989). This effect may not show up in occupational, earnings or income measures, but should be reflected in total net worth.

\section{DATA AND VARIABLES}

The PSID began in 1968 with a nationally representative sample of 5,000 American families and has followed them each year since. Needless to say, it is a complicated study design and cannot be done justice in the space allowed here. For a fuller description, see Hill (1992) or Duncan and Hill (1989). By virtue of this complex design, the study has information on the socioeconomic histories of families as well as on the outcomes of multiple children from the same families who were in the original sample, moved into it, or were born to sample members. We select adult respondents ages 25 and older who were head or wife of their household in any (or all) years between 1983 and 2001. Further, these individuals had to have a valid person number for their mother; that is, their mother had to have been in the sample at some time. They were then linked to their siblings through this maternal connection. A trivial number (less than 1 percent) of respondents had a father in the sample but not a mother. The majority had both parents. But since many more of the fathers were missing, we decided to identify siblings based on their mother's identification. However, results are not statistically different if we rely on the father's identification or include only those who have both parents' sample identifiers. The reason we truncate the person-years at 1983 is that prior to that year "wives" were classified differently: there was no category for cohabiting women (what the PSID subsequently called “wife" in quotes). Further, prior to 1981, occupation—one of our key dependent measures—was 
not coded in the same way (it was coded in a one- or two-digit format in contrast to the standard three-digit census classification used consistently from 1981 onward). For both of these reasons, we truncate the survey years at 1983 .

We examined a number of socioeconomic outcomes and split the sample on a number of different dimensions. The measures that we used to capture siblings' socioeconomic statuses are described below; the unit of analysis is the person-year. Mean values-which generally conform to national averages - are presented in Table 1.

Education: This is measured as total years of formal schooling completed-a continuous variable from 1 to 17 , with the topcode representing any graduate work, regardless of whether a degree was received (the PSID does not, unfortunately, distinguish between various levels of graduate schooling). For our subsample comparison, we split mother's education between high school dropouts and those mothers with a high school degree or better. This proxy for parental SES was preferred to direct measures of parental occupation, earnings, or income since those variables would contain much more missing data since the earliest they could be measured was 1968 (the first survey year)

Occupational Prestige: This is based on Socioeconomic Index Scores (SEI) for 1970 U.S. Census occupational classification codes (Stevens and Featherman 1981). Hodge-Siegel-Rossi prestige scores (1964) return similar results (analyses not shown but available from the authors upon request).

Earnings: This is measured as the total labor market earnings (logged to the base e).

Family Income: We tested a number of formulations of income including logged and unlogged forms; income-to-needs ratios and straight income; and total household income as well 
as individual income. We present sibling correlations for total household income (logged to the base e).

Household Wealth: This variable is taken from the 2001, 1999, 1994, 1989, and 1984 waves of the PSID. As was the case with income, we tried a number of different formulations. The highest sibling correlation appeared to be for the natural logarithm of total net worth minus equity in the main family home-with siblings who had zero or negative values set to zero. We provide sibling correlations for alternative wealth measures in Appendix A.

Socioeconomic Status: We then tested the sibling correlations on a measure of the "class" or socioeconomic status of the respondents. We examined two formulations of this concept: the first was the standardized average of the standardized values of education level, occupational prestige, and income (natural logarithm). The second measure added wealth to this measure, but since wealth is only available for select years, the sample size of person-years for this measure is much lower. The rationale behind this approach is that individuals may be maximizing a latent variable called "class" or "status"; in doing so, they may be making tradeoffs between the various components of social status listed above which lead to lower sibling correlations for each individual measure, while preserving a high degree of social reproduction in the overall latent measure of "class" or "social status." For example, one sister may take a high-prestige occupation that pays little, in contrast to her sister who takes a low-prestige job that pays a lot of money. Under one conceptual model, at least, they would be considered equivalent in socioeconomic status, having comparatively maximized different aspects of SES. An alternative way to think about this composite measure is that each of the individual measures may be subject to a large degree of measurement error and that by averaging them, we reduce the errors-invariables bias in the correlation between siblings. 
Resource Sample Split: The sample is divided along the lines of race (black versus nonblack) and maternal education (12 or more years of schooling versus less than 12 years of schooling). (We also pursued a split along the dimension of family size, as another form of budget constraint, but results were not conclusive and are not presented but are available upon request from the authors.)

Life Course Sample Split: The sample is divided by stage in the life course. Here we compare individuals below age 30 to individuals age 30 to 40 and individuals over age 40 . Individuals from each life course stage are equally distributed across survey years. A frequency distribution of survey years for each stage in the life course reveals a relatively equal distribution across survey years. There are no individuals below age 30 in 2001, and less than 2 percent of observations of individuals below age 30 fall into years 1997, 1998, and 1999. However, these are the only exceptions, and all others are equally distributed across years (distributions available from the authors upon request). This equal distribution across survey years within age categories affords us an examination of effects of age free from effects of cohort.

\section{STATISTICAL APPROACH}

The general approach we take to estimate the sibling resemblance is a variance decomposition method, following the strategy for income used by Mazumder and Levine (2003) and Solon el al. (1991). The total variance of the outcome, $Y_{i j}$, can be expressed as:

$$
\sigma_{\varepsilon}^{2}=E\left(\bar{\varepsilon}-\varepsilon_{i j t}\right)^{2}
$$

This total variance can be decomposed into the sum of expected values of three components (as shown in equation 2 below): the between-family component in permanent status (that is, the difference between the mean for the family $j$ and the grand mean), a within-family component (the difference between the mean for the individual $i$ in family $j$ from the mean for family $j$ ), and a within-subject component (the transitory component of income or wealth; that is, 
the differences between a given year's income or wealth and the mean for that individual). For our single-year measures — the maximized values — the third component essentially drops out of the equation.

$$
\sigma_{z}^{2}=\mathrm{E}\left(\bar{\varepsilon}_{j}-\bar{\varepsilon}^{2}+\left(\bar{\varepsilon}_{v}-\bar{\varepsilon}_{j}\right)^{2}+\left(\varepsilon_{j t}-\bar{\varepsilon}_{v}\right)^{2}\right]
$$

Multiplying this out gives us the well-known formula that the total variance equals the sum of the three variance components minus two times their respective covariances.

$$
\begin{aligned}
& \sigma_{\varepsilon}^{2}=\mathrm{E}\left(\bar{\varepsilon}_{j}-\overline{\mathcal{\varepsilon}}\right)^{2}+\mathrm{E}\left(\bar{\varepsilon}_{i j}-\bar{\varepsilon}_{j}\right)^{2}+\mathrm{E}\left(\varepsilon_{i j t}-\bar{\varepsilon}_{i j}\right)^{2} \\
& -2 \mathrm{E}\left(\bar{\varepsilon}-\bar{\varepsilon}_{j}\right)\left(\varepsilon_{i j}-\bar{\varepsilon}_{j}\right)-2 \mathrm{E}\left(\bar{\varepsilon}_{i j}-\bar{\varepsilon}_{j}\right)\left(\varepsilon_{i j t}-\bar{\varepsilon}_{j t}\right)-2 \mathrm{E}\left(\bar{\varepsilon}-\bar{\varepsilon}_{i j}\right)\left(\varepsilon_{i j t}-\bar{\varepsilon}_{j t}\right)
\end{aligned}
$$

Like others before us (for example, Solon et al. 1991 and Mazumder and Levine 2003), we will proceed (for now) on the assumption that the covariance of between-family, betweensibling, and within-sibling differences is zero. This assumption is akin to positing:

A. No relationship between where your family is on the distribution and how unstable your income (or occupation, education or wealth) is, ...

B. No relationship between where you are relative to your family mean and how unstable your status is, and...

C. No relationship between where your family is in the distribution and the degree of similarity among you and your siblings.

Lemmas A and B are not needed in this analysis, as we interpret sibling correlations in permanent statuses and not sibling correlations in single year measures. We will revisit lemma $\mathrm{C}$ in the analysis of sibling resemblance by race and SES, specifically by testing whether this assumption holds up under varying conditions; but in the meantime, with no covariance by design, the total variance in total SES can thus be represented merely as a sum of the three variance components:

$$
\sigma_{\varepsilon}^{2}=\sigma_{a}^{2}+\sigma_{u}^{2}++\sigma_{v}^{2}
$$

where $\sigma_{a}^{2}$ is the variance between families, and $\sigma_{u}^{2}$ is the variance within families in

permanent status, and $\sigma_{v}^{2}$ is the variance in individual economic characteristics (or transitory 
SES). This assumption of zero covariance—not discussed thoroughly elsewhere—makes the variance decomposition possible and results in a sibling correlation in permanent status according to equation 5 , below.

$$
\rho=\frac{\sigma_{a}^{2}}{\sigma_{a}^{2}+\sigma_{u}^{2}}
$$

We can also estimate $\phi$, the proportion of permanent status that is captured in a single-

year measure:

$$
\phi=\frac{\sigma_{a}^{2}+\sigma_{u}^{2}}{\sigma_{a}^{2}+\sigma_{u}^{2}+\sigma_{v}^{2}}
$$

We examine estimates of sibling correlations in socioeconomic status ( $\rho$ ) using several approaches:

1. We decompose the raw (unadjusted) value on a given measure for those families with two or more siblings with at least one valid person-year each in the sample. (Inclusion of only children - which affect the denominator, that is, total variance — but not the numerator, does not substantially affect our results and these estimates are not presented, though are available from the authors upon request.)

2. We then estimate sibling resemblance in a residual purged of the effects of other socioeconomic outcomes. Meaning, we purge occupational prestige of the effects of education; we purge earnings of the effects of occupational prestige and education; we purge income of the effects of earnings, occupational prestige, and education; and we purge wealth of the effects of income, earnings, occupational prestige, and education. This provides a descriptive account of the associations between sibling statuses as a result of socioeconomic-specific causal processes or as a result of life course sequencing. Hauser et al. (1999) and Warren et al. (2001) find that sibling resemblance in occupational attainment works almost entirely through educational attainment, and we pursue this same research question using additional socioeconomic outcome measures and nationally-representative data. Of course, this approach assumes a unidirectional way to specify the sequencing and results should be interpreted with this in mind. But given the status attainment and life course literatures, this appears to be the most commonsensical ordering of outcomes.

3. Next, we follow our predecessors' lead and estimate sibling resemblance in a residual purged of life cycle and cohort effects. To obtain the residual, the first step is to estimate the following regression: 


$$
y_{i j t}=\beta X_{i j t}+\varepsilon_{i j t}
$$

where the outcome for a given sibling $\mathrm{i}$ in family $\mathrm{j}$ in year $\mathrm{t}$ is shown above as $\mathrm{y}_{\mathrm{ijt}}$. The vector $\mathbf{X}_{\mathrm{ijt}}$ includes dummy variables for respondent's age and survey years to account for career effects and for the timing of exogenous economic shocks. (We also weighted these residuals to see if sample weights affect the correlation in a significant way; they did not, and these results are not presented but are also available upon request from the authors; additionally, we adjusted for autocorrelation in some of our measures, and these results are presented in Appendix B.)

We obtain standard errors for all of our estimates by using the Fisher's z' transformation which converts correlations to the normally distributed variable $z^{\prime}$. The formula for the transformation is: $\mathrm{z}^{\prime}=.5[\ln (1+\rho)-(1-\rho)]$. We then calculate standard errors of $\mathrm{z}^{\prime}$ based on the formula: $\sigma_{z^{\prime}}=1 / \sqrt{ } \mathrm{N}-3$. We test differences across the life course and across resource groups using differences in the Fisher $z^{\prime}$ transformations (in almost every case, differences in transformed correlations are nearly identical to differences in raw correlations).

\section{FINDINGS}

\section{Descriptive Differences in Sibling Correlations across Socioeconomic Outcome Measures}

We first examine whether sibling correlations differ across socioeconomic outcomes and across socioeconomic outcomes while holding other outcomes constant. Table 2, which presents our analysis of the entire sample of PSID siblings, shows that the PSID data yield a correlation of .576 for years of schooling for all siblings. To put this in the context of other previous work, earlier studies such as Hauser and Wong (1989) have suggested that family background accounts for roughly 50 percent of the variation in educational attainment, while Kuo and Hauser (1995) put the figure closer to 60 percent. We interpret this .576 correlation as a descriptive account to which siblings' shared environment, shared genes, and effects on each other shape their educational attainment. In terms of occupational prestige, we find a correlation of .418 , which is lower than the education correlation, and for earnings and income, we find correlations of .376 
and .458 , respectively. ${ }^{5}$ The next two columns show results for global measures of socioeconomic status. The first column shows the standardized combination of education, occupation, and income. The sibling correlation for this measure is .612, higher than for any of the single indicators alone. The second column shows the standardized combination of education, occupation, income and wealth, and this correlation is .605.

Without considering age or resource group, siblings have a .371 correlation in net worth. (Note that this is different from correlations using alternative wealth specifications, provided in Appendix A.) Becker and Tomes' "wealth model" would lead us to expect higher sibling correlations in wealth and lower sibling correlations in human capital, as parents make unequal investments in their children's human capital so as to equalize their earnings and wealth. Behrman et al.'s $(1982,1989)$ "separable earnings-bequest" model would lead us to expect higher correlations in earnings than education. Neither of these parental preference models holds up in our data, especially when we contrast wealth and education correlations.

The second row of Table 2 reports correlations for variables purged of the effects of the socioeconomic outcome(s) that we think precede the current outcome. These correlations are descriptive measures of the associations between sibling statuses that result from inter-sibling effects, shared environments, and shared genes that control for other socioeconomic outcome effects. Unlike the comparisons across socioeconomic outcome raw correlations, findings from this analysis do lend some support to the parental preference models.

\footnotetext{
5 Siblings' correlation in earnings is substantially lower than their correlation in income. In analyses not shown we found a sister correlation in earnings of .273 and a brother correlation in earnings of .498. This is on par with Solon et al.'s (1991) findings of sister correlation of .276 and a brother correlation of .448. We attribute differences between income and earnings correlations to lower sister correlations on earnings because of two different routes to women's economic well-being through marriage and through individual earnings.
} 
Once we account for siblings' educational attainment, we find a significant, albeit significantly reduced, occupational prestige correlation of.09. This supports Hauser et al.'s (1999) and Warren et al.'s (2002) findings of sibling correlations in occupations working largely through education. For earnings, we find that roughly 60 percent of the correlation stays in tact. And the same is true for wealth. Once we control for education, occupation, earnings, and income, the wealth correlation remains roughly intact at .133 . This is about 36 percent of the raw correlation. Finally, income is similar to occupational prestige, in that we find a reduction in significance once we control for earnings, occupational prestige, and education. These findings lend some support to the parental preference models, as these models would lead us to expect residual income, earnings, and wealth correlations after controlling for educational similarities. Findings, however, lend more support to Behrman et al.'s $(1982,1989)$ separable earningsbequest model as it is the wealth correlation which is most resilient to the other control variables. Of course, it is possible that other factors explain the residual correlations in earnings and wealth (such as less measurement error, greater inter-sibling effects for these outcomes).

We explored other sensitivity tests to sibling correlations including considering only children within the sample pool, weighting correlations by PSID sample weights, purging correlations of race and gender effects, purging sibling correlations of age and year effect, weighting sibling correlations, and adjusting for autocorrelation. Results for the first four explorations returned nearly identical sibling correlations (available from the authors upon request), and results for the autocorrelation-adjusted analysis are presented in Appendix B.

\section{Sibling Convergence over the Life Course}

We then examine whether correlations within socioeconomic outcomes shift over the life course (Table 3 ). In summary, our findings indicate that neither $\mathrm{H} 1_{0}$ nor $\mathrm{H} 1_{\mathrm{a}}$ adequately capture 
life course dynamics. Correlations in earnings and income converge across the life course, but correlations in education, occupational prestige, and wealth neither converge nor diverge. Findings reported in Table 3 show that within each age category, correlations for educational attainment are higher than any other outcome measure. Siblings in their twenties (or age 30) have a higher correlation for occupational prestige, .415 , than for earnings, .289 , and income, .356 . This is contrasted to siblings in their thirties (or age 40) that have a higher correlation for income, .432 , than for occupational prestige, .399 , or earnings, .389. Finally, siblings above age 40 have a higher correlation for income, .503 , than for occupational prestige, .396 , or earnings, .338. Nevertheless, these findings challenge parental preference models in that for every age group, siblings have higher educational attainment correlations and lower wealth correlations. Both the wealth model and the separable-earnings bequest model would lead us to expect higher correlations in wealth than in educational attainment, especially in earlier stages of the life course.

When we test differences within socioeconomic outcomes measures and across the life course, we find that outcomes pertaining to earlier life stages (education and occupational attainment) demonstrate early convergence. There is no difference across the life course in sibling correlations for these measures. This can be contrasted to earnings and income where outcomes show a convergence as we move out across the life course stages. For earnings, there is a significant difference between siblings in their twenties and siblings in their thirties such that the former have a .289 correlation in earnings whereas the latter have a .389 correlation in earnings. Earnings seem to solidify in the thirties, as siblings over age 40 do not differ from siblings in their thirties. Family income converges at a later stage. Sibling correlations in income are not significantly different between the first two age groups, whereas correlations show a 
significant increase between the first and third age groups. Siblings in their twenties have a correlation of .356, whereas siblings above age 40 have a correlation of .503 .

Within educational and occupational outcome measures, sibling correlations remain the same, and within earnings and income, siblings tend to converge. This lends support to the equal outcomes parental preference models; however, it could be the result of non-random measurement error. In other words, it could be the case that measurement error in earnings and income is higher for younger adults than it is in older adults. Or, it could be that measurement error early in the life course tends to be of a classic-errors-in-variables type (CEV; that is, random), whereas for older adults it is mean regressive (in other words, siblings tend to bias their answers toward the family mean more when they are older). Education and occupation are presumably measured with less total error.

Results from Table 3 contradict parental preference models especially when we turn to wealth, as these models posit that wealth accrual is a later-life process and that parents may transfer wealth to children in a compensatory fashion. We do not find this to be the casesiblings in their twenties have the same correlation on wealth as siblings in their thirties and siblings older than 40 . This anomalous finding must be interpreted with caution, however, since wealth has a unique distribution making it very difficult to model. First of all, it is right-skewed even more than income; second, it demonstrates a spike at zero; and third, it is measured intermittently by the PSID as compared to the other variables. This last issue is particularly troubling, given that wealth may demonstrate greater measurement error in the cross section (due to its many components and random fluctuation in asset values). 


\section{Sibling Divergence across Population Subgroups}

In the second section of our analysis, we take up the question of whether siblings with more resources and opportunities resemble each other more than siblings with less resources and opportunities. We split our sample by race and maternal educational attainment. While we hypothesized that these two factors are proxy measures of the same underlying factor (lack of resources), our findings suggest that they do not influence sibling associations similarly.

Table 4 reports subgroup comparisons and raw value correlations (using residuals or any of the other formulations does not change the results). In the first two rows of Table 4 we compare sibling correlations on all outcome measures (save the global SES measures) between blacks and nonblacks. We find that sibling resemblance among blacks is much lower than it is for nonblacks on the earnings measure ( $\rho=.088$ and $\rho=.399$ respectively) and on the income measure ( $\rho=.158$ and $\rho=.525$ respectively). Sibling resemblance among blacks and whites does not differ on the other three measures. We will return to this dynamic in the discussion below.

The third and fourth rows of Table 4 report correlations between siblings from higher educated mothers and lower educated mothers. Unlike the race analysis, we find that correlations in earnings and income are not significantly different across the two groups. Correlations in occupational prestige and wealth are significantly different across the two groups with siblings from less educated mothers having higher correlations.

Our final analyses of the interaction between resource group and stage in the life course sheds some light on the contradictory race-class effects on sibling correlations. Table 5 reports correlations in education, occupational prestige, earnings, and income by the three age groups. Cell sizes are relatively small (and so small for wealth as to be meaningless) and reduce our ability to detect significance across groups. In Table 3 we saw that correlations in income 
increased across the life course and in Table 4 we saw that black siblings have much lower correlations than nonblack siblings. Interacting these two factors, we find that black siblings show a dramatic increase in correlations across the life course-from.181 in their twenties to .826 above age 40 . The same cannot be said of nonblacks. Here, we find that nonblack siblings have similar correlations in income in their twenties and above age forty and lower correlations in their thirties $(\rho=.337)$. Maternal education again reveals contrasting results, as sibling correlations converge across the life course on income for siblings with more educated mothers and they do not differ across the life course for siblings with less educated mothers. There appears to be a pair of two-way interactions going on: Life course matters differently by race group and by class group. This finding suggests that constraints and opportunities faced by blacks and nonblacks over the life course differ in ways that work in the opposite direction than SES differences over the life course. Thus, economic models that assume race as a proxy for class, or which ignore race altogether to focus on resource differences only, are inadequate to describe the actual dynamics of family background in American society.

\section{DISCUSSION AND CONCLUSIONS}

We are not the first to propose examining sibling correlations in social and economic status as a way of measuring the effect of measurable and un-measurable family background characteristics (including shared environment, shared genes) and inter-sibling effects on socioeconomic outcomes. For example, Daphne Kuo and Robert Hauser analyze the Occupational Changes in a Generation (OCG) survey data and find that for education, sibling differences (within family variance components) among various age groups of black and white brothers range between 38 percent and 52 percent (see Kuo and Hauser 1995). Mary Corcoran, Roger Gordon, Deborah Laren, and Gary Solon (1990: 364) estimate a brother-brother 
correlation in permanent income of .45 using data from the PSID. Bhashkar Mazumder and David Levine (2003) examine the NLS and the PSID and argue that between the 1960s and the 1970s, the correlation in earnings between brothers rose from .26 to .45. Sibling resemblance in such other outcomes as welfare usage, education, and occupation follow similar patterns and are sensitive to the specification deployed-particularly for nonlinear measures. For example, if a woman's sister has received welfare, she is over three times more likely to receive it herself (.66 versus .20 probability in their PSID sample).

When we reanalyze more recent waves of PSID data-in which the siblings are on average older and more stable economically_-with a substantially larger sample size of personyears and sibling sets, we obtain similar estimates of the association between siblings on education, occupational prestige, and earnings.

Our analyses further build on these previous studies by exploring two questions regarding sibling convergence or divergence across the life course and across population subgroup. And we report three new findings: 1. Family background (representing shared environment, shared genetic endowments, and inter-sibling effects) appears to relate to earnings net of education, occupation, and income and relates to wealth net of education, occupation, income, and earnings. This suggests that the effects of shared genes, environment and inter-sibling effects are not just confined to the educational system, but also affect labor market, marriage and savings, investment, and inheritance dynamics; 2 . Siblings converge in outcomes that take longer to stabilize (income and earnings) and remain similar across the life course in outcomes that stabilize early on (education and occupational prestige); and finally, 3. Black siblings have significantly lower correlations on economic outcomes measures (specifically, income and earnings) than nonblack siblings, and black siblings dramatically converge in income across the 
life course-in their twenties black siblings have a .181 correlation in income and above age forty they have a .826 correlation in income. This pattern does not hold for nonblack siblings. These findings complicate economic parental preference models and life course and status attainment sequencing models. Parental preference models would lead us to expect significant residual correlations in earnings (according to Behrman et al.'s separable earningsbequest model) and significant residual correlations in wealth (according to Becker and Tomes' wealth model), and that we found. Roughly 60 percent of siblings' resemblance in earnings remains after controlling for occupational prestige and education, and 36 percent of siblings' resemblance in wealth remains in tact after controlling for education, occupational prestige, earnings, and family income. However, it could be the case that the residual correlation in earnings is not a function of parental compensatory investment strategies but rather merely the fact that years of schooling is a poor proxy for human capital accumulation in that it ignores similarity in the status and quality of education obtained by siblings. In other words, earnings similarity may be reflecting unmeasured sibling similarity in education (and occupation, for that matter).

Furthermore, parental preference models are challenged when we look to results across socioeconomic outcome measures and within age categories in that sibling correlations in wealth remain consistently lower than sibling correlations in income (as well as education and occupational prestige). Parental preference models would lead us to expect the opposite- that parents invest unequally in their children's education so as to efficiently maximize the return on ability endowments, but then seek to equalize sibling economic status when it comes to nonhuman capital measures. Our findings also lend some support to stratification and life course models in that we find that siblings resemble each other on socioeconomic outcomes pertaining 
to earlier life events (those with less exposure to chance factors). However, when we analyze age effects directly, we find that siblings converge in income and earnings, and this would not be expected given Jencks' (1972) and others' theory of declining sibling resemblance in income due to chance events. Rather, the findings of convergence in economic status could be due to a greater degree of measurement error (of a classic errors-in-variables type) of earnings and income earlier in the life course; or it could be because of the emergent salience of shared genes; alternatively, it could be due to an increase in direct inter-sibling effects in adulthood as we age (though this seems improbable in American society); or it could be the result of compensatory parental impacts later in life (though also this seems unlikely). At any rate, it suggests that if studies analyze economic correlations earlier in adulthood, they may be underestimating the degree of sibling similarity (and thus overstating the amount of income mobility) in the United States. This dynamic, as we will see below, holds particularly true for blacks.

Whereas Becker and Tomes (1986) predict and Mazumder and Levine (2003) find that siblings who have fewer economic resources tend to demonstrate greater concordance in their socioeconomic statuses we find mixed evidence on this front. Sibling correlations in earnings and income are not significantly different across mother's educational status (confounding their expectations), but sibling correlations in occupation and wealth are significantly higher for mothers with lower educational attainment (lending support to their theories). Further complicating the picture, we report strong race effects such that black siblings resemble each other less on earnings and income than nonblack siblings—obliquely supporting previous sociological work that has suggested weaker family effects for blacks vis-à-vis whites with respect to occupation and education because of dynamics of discrimination and tokenism (see, for example, Blau and Duncan 1967; Featherman and Hauser 1978). (We say obliquely since we 
do not find significant racial differences when it comes to the very measures upon which these previous researchers have relied—education and occupational prestige.)

However, when we interact age with race or class, the results are not so straightforward. When we break out income correlations over the life course by maternal education level (as a proxy for the SES of the family of origin) we find that the similarity in income among siblings from more highly educated mothers tends to increase with age, peaking at a figure of .537 for the 40-year-old plus group (while declining [insignificantly] over the life course among siblings born to mothers with less education, to a .329 level for the oldest group). This offers a challenge to the Becker-Tomes prediction about resource group differences. But when we examine the interaction of life course and racial differences we find that black siblings converge in income whereas nonblack siblings do not converge in income as they age. This convergence in income-coupled with no convergence in earnings — suggests that marital and/or transfer processes underlie black siblings' later-life resemblance. Assuming that there is no significant difference in the genetic similarity between black siblings in comparison with white siblings (or at least not great enough to explain the large differences we find), race differences in sibling similarity point to the salience of opportunity structures and/or parenting strategies. So when we interact race and age, we contradict previous findings that black siblings have weaker family effects. Indeed, among the oldest age group, the black sibling correlation in income is a staggering .826—suggesting almost complete social reproduction in living standards by the fifth decade of life. (While statistically significant, we should keep in mind that this race-age analysis is based on a very small set of age 40 or older black siblings.) When contrasted to the opposite age-class interaction effect whereby the more advantaged group experiences income convergence while the lessadvantaged group does not, these results suggest, but by no means prove, that the American 
stratification system functions differently for blacks and whites in a way that is not reducible to resource issues alone - a proposition that begs for future research. For now, it is worth noting that researchers may get very different answers to the seemingly simple descriptive question about how much income mobility there is in America depending on the age at which they measure economic status and the group(s) to which they are referring. Future researchers should perhaps refrain from using overall sibling correlations to make "global" assessments of the degree of openness in American society, as the answer appears to depend on the race-class group under study and the age group to which we are referring. 


\section{REFERENCES}

Acker, Joan. 1973. "Women and Social Stratification: A Case of Intellectual Sexism.” American Journal of Sociology 78: 936-945.

Becker, Gary S. and Nigel Tomes. 1979. "Equilibrium-Theory of the Distribution of Income and Intergenerational Mobility." Journal of Political Economy 87: 1153-1189.

. 1976. "Child Endowments and Quantity and Quality of Children.” Journal of Political Economy 84: S143-S162.

. 1986. "Human Capital and the Rise and Fall of Families." Journal of Labor Economics 4:S1-S39.

Behrman, Jere R., Zdenek Hrubec, Paul Taubman, and T. Wales. 1980. Socioeconomic Success: A Study of the Effects of Genetic Endowments, Family Environment, and Schooling. Amsterdam: North Holland Publishing Company

Behrman, Jere R., and Paul Taubman. 1990. "The Intergenerational Correlation between Children's Adult Earnings and their Parents' Income: Results from the Michigan Panel Survey of Income Dynamics." The Review of Income and Wealth 46: 115-127.

Behrman, Jere R., Robert A. Pollak, and Paul Taubman. 1982. "Parental Preferences and Provision for Progeny." Journal of Political Economy 90: 52-73.

. 1989. "Family Resources, Family-Size, and Access to Financing for CollegeEducation.” Journal of Political Economy 97: 398-419

1995. From Parent to Child: Intrahousehold Allocation and Intergenerational Relations in the United States. Chicago: University of Chicago Press.

Behrman, Jere, Mark Rosenzweig, and Paul Taubman. 1994. "Endowments and the Allocation of Schooling in the Family and in the Marriage Market: The Twins Experiment." The Journal of Political Economy 102: 1131-1174.

Benin, Mary H., and David R. Johnson. 1984. "Sibling Similarities in Educational Attainment: A Comparison of Like-Sex and Cross-Sex Sibling Pairs." Sociology of Education 57: 1121.

Biblarz, Timothy J., Alexander Bucar, and Vern L. Bengston. 1996. "Social Mobility Across Three Generations." Journal of Marriage and the Family 58: 188-200.

Blau, Peter, and Otis D. Duncan. 1967. The American Occupational Structure. New York: Free Press. 
Charles, Kerwin Kofi, and Erik Hurst. 2003. "The Correlation of Wealth across Generations." Journal of Political Economy 111: 1155-1182.

Cherlin, Andrew. 1992. Marriage, Divorce, Remarriage. Cambridge, MA: Harvard University Press.

Conley, Dalton. 1999. Being Black, Living in the Red: Race, Wealth, and Social Policy in America. Berkeley: University of California Press. . 2004. The Pecking Order: Which Siblings Succeed and Why. New York: Pantheon Books.

Conley, Dalton, and Neil G. Bennett. 2000. "Is Biology Destiny? Birth Weight and Life Chances." American Sociological Review 65: 458-467.

Conley, Dalton, Rebecca Glauber, and Sheera Olasky. 2004. "Sibling Similarity and Difference in Socioeconomic Status.” Institute for Research on Poverty, Discussion Paper 1291-04.

Corcoran, Mary, Roger Gordon, Deborah Laren, and Gary Solon. 1990. "Poverty and the Underclass: Effects of Family and Community Background on Economic Status." American Economic Review 80: 362-866.

Duncan, Greg J., and Daniel Hill. 1989. “Assessing the Quality of Household Panel Survey Data: The Case of the PSID." Journal of Business and Economic Statistics 7(4): 441-451.

Elder, Glen H., Jr. 1985. Life Course Dynamics: Trajectories and Transitions, 1968-1980. Ithaca, NY: Cornell University Press.

Featherman, David, and Robert Hauser. 1978. Opportunity and Change. New York: Academic Press.

M.W. Feldman and R.C. Lewontin. 1975. “The Heritability Hangup.” Science 190: 1163-1168.

Furstenberg, Frank Jr., and Andrew Cherlin. 1991. Divided Families: What Happens to Children When Parents Part. Cambridge, MA: Harvard University Press.

Gerson, Kathleen. 1993. No Man's Land: Men's Changing Commitments to Family and Work. New York: Basic Books.

Goldberger, Arthur 1977. "Twin Methods: A Skeptical View.” Pp. 299-324 in Paul Taubman, ed., Kinometrics: Determinants of Socioeconomic Success within and between Families. Amsterdam: North-Holland Publishing Company. . 1979. "Heritability." Economica. 46:327-347.

Goldthorpe, John. 1983. "Women and Class Analysis: In Defense of the Conventional View." Sociology: 17. 
Gottesman, I.I. and J. Shields. 1982. Schizophrenia: The Epigenetic Puzzle. Cambridge: Cambridge University Press.

Grusky, David B., and Thomas A. DiPrete. 1990. "Recent Trends in the Process of Stratification.” Demography 27:617-637.

Hauser, Robert M., Jennifer T. Sheridan, and John Robert Warren. 1999. "Socioeconomic Achievements of Siblings in the Life Course - New Findings from the Wisconsin Longitudinal Study." Research on Aging 21: 338-378.

Hauser, Robert M., and P. Mossel. 1985. "Fraternal Resemblance in Educational Attainment and Occupation." American Journal of Sociology 91: 650-673.

Hauser, Robert M., and William Sewell. 1986. "Family Effects in Simple Models of Education, Occupational Status, and Earnings: Findings from the Wisconsin and Kalamazoo Studies." Journal of Labor Economics 4: S83-S115.

Hauser, Robert, and R. Wong. 1989. "Sibling Resemblance and Intersibling Effects in Educational Attainment." Sociology of Education 62: 149-171.

Hill, Martha S. 1992. The Panel Study of Income Dynamics: A User's Guide. Newbury Park, CA: Sage Publications.

Hodge, Robert W., Paul M. Siegel, and Peter H. Rossi. 1964. "Occupational Prestige in the United States, 1925-1963." American Journal of Sociology 70: 286-302.

Hout, Michael. 1988. "More Universalism, Less Structural Mobility: The American Occupational Structure in the 1980s." American Journal of Sociology 93: 1358-1400.

Jantti, Markus, Eva Osterbacka, Oddbjorn Raaum, Tor Eriksson, and Anders Bjorklund. 2002. "Brother Correlations in Earnings in Denmark, Finland, Norway and Sweden Compared to the United States." Journal of Population Economics 15: 757-772.

Jencks, Christopher. 1972. Inequality: A Reassessment of the Effect of Family and Schooling in America. New York: Basic Books.

Jencks, Christopher S., S. Bartlett, M. Corcoran, J. Crouse, D. Eaglesfield, G. Jackson, K. McClelland, P. Mueser, M. Olneck, J. Schwartz, S. Ward, and J. Williams. 1979. Who Gets Ahead? The Determinants of Economic Success in America. New York: Basic Books.

Keister, Lisa A. 2000. Wealth in America. Cambridge: Cambridge University Press.

Kendler, K.S. and C.D. Robinette. 1983. "Schizophrenia in the National Academy of SciencesNational Research Council twin registry: A 16-year update." American Journal of Psychiatry. 140:1551-1563. 
Kuo, H-H. Daphne, and Robert M. Hauser. 1995. "Trends in Family Effects on the Education of Black and White Brothers." Sociology of Education 68: 136-160.

Layzer, D. 1974. "Heritability Analyses of IQ Scores: Science or Numerology?” Science 183: 1259-1266.

Levine, David I., and Bhashkar Mazumder. 2002. "Choosing the Right Parents: Changes in the Intergenerational Transmission of Inequality Between 1980 and the Early 1990s." Federal Reserve Bank of Chicago, Working Paper Series WP-02-08, Federal Reserve Bank of Chicago.

Mayer, Karl Ulrich, and Urs Schoepflin. 1989. "The State and the Life Course." Annual Review of Sociology 15: 187-209.

Mayer, Susan E., and Leonard M. Lopoo. 2005. "Has the Intergenerational Transmission of Economic Status Changed?” Journal of Human Resources 40: 169-185.

Mazumder, Bhashkar, and David I. Levine. 2003. "The Growing Importance of Family and Community: An Analysis of Changes in the Sibling Correlation in Earnings." Federal Reserve Bank of Chicago, Working Paper 2003-24.

Oliver, Melvin L., and Thomas M. Shapiro. 1995. Black Wealth/White Wealth: A New Perspective on Racial Inequality. New York: Routledge.

Plomin, R. 1986. Development, Genetics and Psychology. Hillsdale, NJ: Erlbaum.

. 1988. "The Nature and Nurture of Cognitive Abilities." In Advances in the Psychology of Human Intelligence, ed. R.J. Sternberg. Hillsdale, N.J.: Erlbaum.

Reich, T., P. Van Eerdewegh, J.Rice, J. Mullaney, J. Endicott and G.L. Klerman. 1987. “The Familial Transmission of Primary Major Depressive Disorder." Journal of Psychiatric Research. 21:613-624.

Plomin, R. and D. Daniels. 1987. "Why are Children in the Same Family so Different From Each Other?" Behavioral and Brain Sciences. 10:1-16.

Plomin, R., J.C. DeFries and J.C. Loehlin. 1989. Behavioral Genetics: A Primer. 2nd Edition. New York: W.H. Freeman.

Rindfuss, Ronald R., C. Gray Swicegood, and Rachel A. Rosenfeld. "Disorder in the Life Course: How Common and Does it Matter?" American Sociological Review 52: 785-801.

Rowe, D. 1981. "Environmental and Genetic Influences on Dimensions of Perceived Parenting: A Twin Study." Developmental Psychology. 17:203-208.

Solon, Gary, Mary Corcoran, Roger Gordon, and Deborah Laren. 1991. "A Longitudinal Analysis of Sibling Correlation in Economic Status.” Journal of Human Resources 26: 509-534. 
Solon, Gary, Marianne E. Page, and Greg J. Duncan. 2000. "Correlations Between Neighboring Children in their Subsequent Educational Attainment." Review of Economics and Statistics 82: 383-392.

Stevens, Gillian and David L. Featherman. 1981. "A Revised Socioeconomic Index for Occupational Status.” Social Science Research 10: 364-393.

Teachman, Jay. 1995. "Sibling Resemblance and Symmetry in Intellectual Skill." Sociology of Education 68: 205-220.

Teachman, Jay, Karen Carver, and R. Day. 1995. "A Model for the Analysis of Paired Data." Journal of Marriage and the Family 67: 1011-1024.

Warren, John Robert. 2001. "Changes with Age in the Process of Occupational Stratification.” Social Science Research 30: 264-288.

Warren, John Robert, Jennifer T. Sheridan, and Robert M. Hauser. 2002. “Occupational Stratification across the Life Course: Evidence from the Wisconsin Longitudinal Study." American Sociological Review 67: 432-455. 
TABLE 1

Descriptive Statistics: Means for Families with Two or More Siblings (Standard Deviations, and Within-Family Standard Deviations Below)

\begin{tabular}{|c|c|c|c|c|c|}
\hline & Education & Occupational Prestige & Ln Earnings & Ln Total Family Income & Ln Total Net Worth \\
\hline \multirow{3}{*}{ Total Sample } & 13.61 & 43.91 & 10.13 & 10.52 & 8.70 \\
\hline & 2.26 & 14.48 & 0.91 & 1.32 & 3.97 \\
\hline & 0.28 & 7.41 & 0.62 & 1.05 & 2.35 \\
\hline \multirow[t]{3}{*}{ Black } & 0.07 & 0.07 & 0.06 & 0.08 & 0.08 \\
\hline & 0.25 & 0.26 & 0.24 & 0.27 & 0.27 \\
\hline & 0.00 & 0.00 & 0.00 & 0.00 & 0.00 \\
\hline Mother's Educational & 11.86 & 11.92 & 11.89 & 11.85 & 11.88 \\
\hline Attainment (for outcome & 2.68 & 2.64 & 2.66 & 2.68 & 2.68 \\
\hline measure not missing) & 0.00 & 0.00 & 0.00 & 0.00 & 0.00 \\
\hline Age (for outcome measure & 36.39 & 36.58 & 34.96 & 36.75 & 38.40 \\
\hline \multirow[t]{2}{*}{ not missing) } & 7.41 & 7.25 & 6.61 & 7.55 & 7.89 \\
\hline & 4.93 & 4.64 & 4.05 & 4.76 & 5.05 \\
\hline Number of Person-Years & 25,554 & 15,277 & 20,792 & 18,144 & 5,041 \\
\hline Number of Individuals & 1,777 & 1,388 & 1,876 & 1,871 & 1,767 \\
\hline
\end{tabular}




\section{TABLE 2}

PSID Sibling Correlations: 1983-2001 Waves (Number of Person-Years, Number of Individuals, and Number of Families Below)

\begin{tabular}{|c|c|c|c|c|c|c|c|}
\hline & Education & Occ. Prestige (SEI) & Ln Earnings & Ln Income & $\begin{array}{c}\text { Ln Net Worth } \\
\text { (minus home equity) }\end{array}$ & $\begin{array}{l}\text { Class Position I } \\
\text { (educ, occ, } \ln \\
\text { income) }\end{array}$ & $\begin{array}{l}\text { Class Position II } \\
(+\ln \text { net worth) }\end{array}$ \\
\hline \multirow[t]{6}{*}{ Actual Value } & $0.576^{* * *}$ & $0.418 * * *$ & $0.376^{* * *}$ & $0.458 * * *$ & $0.371 * * *$ & $0.612 * * *$ & $0.605 * * *$ \\
\hline & 0.657 & 0.445 & 0.395 & 0.495 & 0.390 & 0.712 & 0.701 \\
\hline & 0.036 & 0.036 & 0.035 & 0.035 & 0.035 & 0.039 & 0.039 \\
\hline & 25,554 & 20,146 & 20,792 & 18,144 & 5,041 & 14,808 & 3,899 \\
\hline & 1,777 & 1,859 & 1,876 & 1,871 & 1,871 & 1,297 & 1,194 \\
\hline & 780 & 794 & 801 & 806 & 806 & 672 & 645 \\
\hline Residual Purified of & \multirow{6}{*}{ N/A } & $0.091 *$ & $0.229 * * *$ & 0.061 & $0.133 * * *$ & \multirow{6}{*}{ N/A } & \multirow{6}{*}{ N/A } \\
\hline Socioeconomic Outcome & & 0.091 & 0.233 & 0.061 & 0.134 & & \\
\hline \multirow[t]{4}{*}{ Measure(s) to the Left } & & 0.036 & 0.036 & 0.037 & 0.039 & & \\
\hline & & 19,651 & 18,008 & 12,690 & 3,033 & & \\
\hline & & 1,737 & 1,733 & 1,591 & 1,196 & & \\
\hline & & 766 & 766 & 741 & 649 & & \\
\hline
\end{tabular}


TABLE 3

PSID Sibling Correlations: 1983-2001 Waves by Lifecourse (Fisher's z transformation, Standard Error of z, Number of Person-Years, Number of Individuals, and Number of Families Below)

\begin{tabular}{|c|c|c|c|c|c|}
\hline & Education & $\begin{array}{l}\text { Occ. Prestige } \\
\text { (SEI) }\end{array}$ & Ln Earnings & Ln Income & $\begin{array}{l}\text { Ln Net Worth } \\
\text { (minus home } \\
\text { equity) }\end{array}$ \\
\hline \multirow[t]{6}{*}{ Age: $\leq 30$ Years } & 0.556 & 0.415 & 0.289 & 0.356 & 0.345 \\
\hline & 0.627 & 0.441 & 0.297 & 0.372 & 0.360 \\
\hline & 0.039 & 0.040 & 0.039 & 0.041 & 0.045 \\
\hline & 6,113 & 5,223 & 6,013 & 4,177 & 868 \\
\hline & 1,338 & 1,269 & 1,357 & 1,093 & 786 \\
\hline & 644 & 627 & 653 & 590 & 489 \\
\hline \multirow[t]{6}{*}{ Age: $31-40$ Years } & 0.565 & 0.399 & 0.389 & 0.432 & 0.369 \\
\hline & 0.641 & 0.422 & 0.410 & 0.463 & 0.387 \\
\hline & 0.037 & 0.037 & 0.037 & 0.037 & 0.038 \\
\hline & 12,513 & 10,069 & 10,618 & 8,672 & 2,278 \\
\hline & 1,642 & 1,664 & 1,694 & 1,593 & 1,319 \\
\hline & 729 & 739 & 741 & 726 & 678 \\
\hline \multirow[t]{6}{*}{ Age: $>40$ Years } & 0.592 & 0.396 & 0.338 & 0.503 & 0.346 \\
\hline & 0.681 & 0.419 & 0.352 & 0.554 & 0.361 \\
\hline & 0.044 & 0.044 & 0.046 & 0.043 & 0.043 \\
\hline & 6,928 & 4,854 & 4,161 & 5,295 & 1,895 \\
\hline & 996 & 998 & 846 & 1,043 & 1,006 \\
\hline & 530 & 527 & 476 & 545 & 536 \\
\hline Difference between $\leq 30 \& 31-40$ & -0.014 & 0.019 & $-0.113^{*}$ & -0.091 & -0.027 \\
\hline Standard Error of Difference & 0.054 & 0.054 & 0.054 & 0.056 & 0.059 \\
\hline Difference between $\leq 30 \&>40$ & -0.055 & 0.022 & -0.055 & $-0.182 * *$ & -0.001 \\
\hline Standard Error of Difference & 0.059 & 0.059 & 0.060 & 0.060 & 0.063 \\
\hline Difference between $31-40 \&>40$ & -0.041 & 0.003 & 0.058 & -0.091 & 0.026 \\
\hline Standard Error of Difference & 0.057 & 0.057 & 0.059 & 0.057 & 0.058 \\
\hline
\end{tabular}




\section{TABLE 4}

PSID Sibling Correlations: 1983-2001 Waves by Subgroups (Fisher's z transformation, Standard Errors of z, Number of Person-Years, Number of Individuals, Number of Families Below)

\begin{tabular}{|c|c|c|c|c|c|}
\hline & Education & Occ. Prestige & Ln Earnings & Ln Income & $\begin{array}{c}\text { Ln Net Worth } \\
\text { (minus home } \\
\text { equity) }\end{array}$ \\
\hline \multirow[t]{6}{*}{ Black } & 0.548 & 0.566 & 0.088 & 0.158 & 0.538 \\
\hline & 0.615 & 0.642 & 0.088 & 0.159 & 0.601 \\
\hline & 0.134 & 0.130 & 0.131 & 0.130 & 0.137 \\
\hline & 1447 & 1076 & 1096 & 1248 & 352 \\
\hline & 108 & 118 & 117 & 120 & 113 \\
\hline & 59 & 62 & 61 & 62 & 56 \\
\hline \multirow[t]{6}{*}{ Nonblack } & 0.571 & 0.413 & 0.399 & 0.525 & 0.331 \\
\hline & 0.648 & 0.439 & 0.422 & 0.583 & 0.344 \\
\hline & 0.039 & 0.039 & 0.039 & 0.039 & 0.039 \\
\hline & 20270 & 16083 & 16507 & 14673 & 4110 \\
\hline & 1342 & 1410 & 1426 & 1408 & 1346 \\
\hline & 655 & 666 & 675 & 675 & 663 \\
\hline Difference & -0.033 & 0.203 & $-0.334 *$ & $-0.424 * *$ & 0.257 \\
\hline Standard Error of Difference & 0.139 & 0.136 & 0.137 & 0.136 & 0.143 \\
\hline Mother Has Less Than 12 Years & 0.547 & 0.492 & 0.348 & 0.466 & 0.549 \\
\hline \multirow[t]{5}{*}{ Education } & 0.614 & 0.539 & 0.363 & 0.505 & 0.617 \\
\hline & 0.069 & 0.069 & 0.068 & 0.068 & 0.069 \\
\hline & 7026 & 5234 & 5526 & 4982 & 1364 \\
\hline & 507 & 518 & 522 & 526 & 481 \\
\hline & 216 & 215 & 217 & 220 & 212 \\
\hline \multirow[t]{6}{*}{ Mother Has 12+ Years Education } & 0.477 & 0.321 & 0.331 & 0.359 & 0.277 \\
\hline & 0.519 & 0.333 & 0.344 & 0.375 & 0.284 \\
\hline & 0.042 & 0.042 & 0.041 & 0.041 & 0.042 \\
\hline & 18528 & 14912 & 15266 & 13162 & 3677 \\
\hline & 1270 & 1341 & 1354 & 1345 & 1286 \\
\hline & 564 & 579 & 584 & 586 & 576 \\
\hline Difference & 0.070 & $0.171 *$ & 0.017 & 0.107 & $0.272 * * *$ \\
\hline Standard Error of Difference & 0.080 & 0.080 & 0.080 & 0.080 & 0.081 \\
\hline
\end{tabular}

$* \mathrm{p}<.05 ; * * \mathrm{p}<.01 ; * * * \mathrm{p}<001$ (two-tailed tests) 
TABLE 5

PSID Sibling Correlations: 1983-2001 Waves by Lifecourse and Subgroups (Fisher's z transformation, Standard Error of z, Number of Person-Years, Number of Individuals, and Number of Families Below)

\begin{tabular}{|c|c|c|c|c|c|}
\hline & & Education & Occ. Prestige & Ln Earnings & Ln Income \\
\hline \multirow{18}{*}{ Black } & \multirow{6}{*}{ Age: $\leq 30$ Years } & 0.362 & 0.519 & 0.050 & 0.181 \\
\hline & & 0.379 & 0.575 & 0.050 & 0.183 \\
\hline & & 0.154 & 0.160 & 0.156 & 0.160 \\
\hline & & 361 & 295 & 337 & 308 \\
\hline & & 83 & 75 & 82 & 74 \\
\hline & & 45 & 42 & 44 & 42 \\
\hline & \multirow{6}{*}{ Age: $31-40$ Years } & 0.412 & 0.540 & 0.246 & 0.535 \\
\hline & & 0.438 & 0.604 & 0.251 & 0.597 \\
\hline & & 0.140 & 0.140 & 0.140 & 0.146 \\
\hline & & 684 & 512 & 538 & 584 \\
\hline & & 91 & 93 & 94 & 88 \\
\hline & & 54 & 54 & 54 & 50 \\
\hline & \multirow{6}{*}{ Age: $>40$ Years } & 0.583 & 0.712 & 0.048 & 0.826 \\
\hline & & 0.667 & 0.892 & 0.048 & 1.174 \\
\hline & & 0.169 & 0.167 & 0.183 & 0.162 \\
\hline & & 402 & 269 & 221 & 356 \\
\hline & & 58 & 65 & 54 & 68 \\
\hline & & 38 & 39 & 33 & 41 \\
\hline Difference between $\leq 30 \& 31-40$ & & -0.059 & -0.029 & -0.201 & -0.414 \\
\hline Standard Error of Difference & & 0.208 & 0.213 & 0.210 & 0.217 \\
\hline Difference between $\leq 30 \&>40$ & & -0.288 & -0.316 & 0.002 & $-0.991 * * *$ \\
\hline Standard Error of Difference & & 0.229 & 0.231 & 0.240 & 0.228 \\
\hline Difference between $31-40 \&>40$ & & -0.230 & -0.288 & 0.203 & $-0.578 * *$ \\
\hline Standard Error of Difference & & 0.219 & 0.218 & 0.230 & 0.218 \\
\hline \multirow{18}{*}{ Nonblack } & \multirow{6}{*}{ Age: $\leq 30$ Years } & 0.574 & 0.431 & 0.324 & 0.558 \\
\hline & & 0.653 & 0.461 & 0.336 & 0.629 \\
\hline & & 0.043 & 0.044 & 0.043 & 0.046 \\
\hline & & 4,550 & 3,902 & 4,517 & 3,091 \\
\hline & & 993 & 945 & 1,013 & 782 \\
\hline & & 536 & 524 & 546 & 481 \\
\hline & \multirow{6}{*}{ Age: $31-40$ Years } & 0.553 & 0.392 & 0.412 & 0.337 \\
\hline & & 0.623 & 0.414 & 0.438 & 0.351 \\
\hline & & 0.040 & 0.040 & 0.040 & 0.041 \\
\hline & & 9,865 & 8,030 & 8,445 & 6,994 \\
\hline & & 1,265 & 1,285 & 1,310 & 1,214 \\
\hline & & 620 & 626 & 631 & 611 \\
\hline & \multirow{6}{*}{ Age: $>40$ Years } & 0.589 & 0.368 & 0.348 & 0.516 \\
\hline & & 0.676 & 0.386 & 0.363 & 0.571 \\
\hline & & 0.047 & 0.047 & 0.050 & 0.046 \\
\hline & & 5,855 & 4,151 & 3,545 & 4,588 \\
\hline & & 820 & 827 & 699 & 861 \\
\hline & & 455 & 450 & 407 & 467 \\
\hline Difference between $\leq 30 \& 31-40$ & & 0.030 & 0.047 & -0.102 & $0.279 * * *$ \\
\hline Standard Error of Difference & & 0.059 & 0.059 & 0.059 & 0.061 \\
\hline Difference between $\leq 30 \&>40$ & & -0.023 & 0.075 & -0.027 & 0.058 \\
\hline Standard Error of Difference & & 0.064 & 0.064 & 0.066 & 0.065 \\
\hline Difference between $31-40 \&>40$ & & -0.053 & 0.029 & 0.075 & $-0.220 * * *$ \\
\hline Standard Error of Difference & & 0.062 & 0.062 & 0.064 & 0.062 \\
\hline
\end{tabular}

(table continues) 


\begin{tabular}{|c|c|c|c|c|c|}
\hline & & Education & Occ. Prestige & Ln Earnings & Ln Income \\
\hline \multirow{18}{*}{$\begin{array}{l}\text { Mother Has Less than } 12 \text { Years } \\
\text { Education }\end{array}$} & \multirow{6}{*}{ Age: $\leq 30$ Years } & 0.420 & 0.379 & 0.232 & 0.373 \\
\hline & & 0.447 & 0.399 & 0.237 & 0.392 \\
\hline & & 0.080 & 0.083 & 0.080 & 0.085 \\
\hline & & 1,554 & 1,229 & 1,470 & 1,050 \\
\hline & & 350 & 312 & 345 & 271 \\
\hline & & 160 & 147 & 159 & 141 \\
\hline & \multirow{6}{*}{ Age: $31-40$ Years } & 0.533 & 0.455 & 0.381 & 0.331 \\
\hline & & 0.595 & 0.492 & 0.401 & 0.344 \\
\hline & & 0.074 & 0.074 & 0.073 & 0.075 \\
\hline & & 3,285 & 2,523 & 2,739 & 2,264 \\
\hline & & 444 & 437 & 449 & 421 \\
\hline & & 188 & 186 & 189 & 181 \\
\hline & \multirow{6}{*}{ Age: > 40 Years } & 0.550 & 0.563 & 0.132 & 0.329 \\
\hline & & 0.619 & 0.637 & 0.133 & 0.341 \\
\hline & & 0.080 & 0.081 & 0.084 & 0.080 \\
\hline & & 2,187 & 1,482 & 1,317 & 1,668 \\
\hline & & 299 & 291 & 255 & 308 \\
\hline & & 159 & 155 & 144 & 161 \\
\hline Difference between $\leq 30 \& 31-40$ & & -0.148 & -0.092 & -0.164 & 0.047 \\
\hline Standard Error of Difference & & 0.109 & 0.111 & 0.109 & 0.113 \\
\hline Difference between $\leq 30 \&>40$ & & -0.171 & $-0.238 *$ & 0.104 & 0.050 \\
\hline Standard Error of Difference & & 0.113 & 0.116 & 0.116 & 0.117 \\
\hline Difference between $31-40 \&>40$ & & -0.024 & -0.146 & $0.268^{*}$ & 0.003 \\
\hline Standard Error of Difference & & 0.109 & 0.110 & 0.112 & 0.109 \\
\hline \multirow{18}{*}{ Mother Has 12+ Years Education } & \multirow{6}{*}{ Age: $\leq 30$ Years } & 0.502 & 0.339 & 0.265 & 0.261 \\
\hline & & 0.552 & 0.353 & 0.272 & 0.267 \\
\hline & & 0.046 & 0.046 & 0.045 & 0.047 \\
\hline & & 4,559 & 3,994 & 4,543 & 3,127 \\
\hline & & 988 & 957 & 1,012 & 822 \\
\hline & & 484 & 480 & 494 & 449 \\
\hline & \multirow{6}{*}{ Age: $31-40$ Years } & 0.467 & 0.304 & 0.332 & 0.390 \\
\hline & & 0.507 & 0.314 & 0.345 & 0.412 \\
\hline & & 0.043 & 0.043 & 0.043 & 0.043 \\
\hline & & 9,228 & 7,546 & 7,879 & 6,408 \\
\hline & & 1,198 & 1,227 & 1,245 & 1,172 \\
\hline & & 541 & 553 & 552 & 545 \\
\hline & \multirow{6}{*}{ Age: $>40$ Years } & 0.472 & 0.267 & 0.371 & 0.537 \\
\hline & & 0.513 & 0.273 & 0.390 & 0.600 \\
\hline & & 0.052 & 0.052 & 0.055 & 0.051 \\
\hline & & 4,741 & 3,372 & 2,844 & 3,627 \\
\hline & & 697 & 707 & 591 & 735 \\
\hline & & 371 & 372 & 332 & 384 \\
\hline Difference between $\leq 30 \& 31-40$ & & 0.045 & 0.039 & -0.073 & $-0.145^{*}$ \\
\hline Standard Error of Difference & & 0.063 & 0.063 & 0.062 & 0.064 \\
\hline Difference between $\leq 30 \&>40$ & & 0.039 & 0.079 & -0.118 & $-0.333 * * *$ \\
\hline Standard Error of Difference & & 0.069 & 0.069 & 0.071 & 0.070 \\
\hline Difference between $31-40 \&>40$ & & -0.007 & 0.040 & -0.045 & $-0.188 * *$ \\
\hline Standard Error of Difference & & 0.068 & 0.067 & 0.070 & 0.067 \\
\hline
\end{tabular}

$* \mathrm{p}<.05 ; * * \mathrm{p}<.01 ; * * * \mathrm{p}<001$ (two-tailed tests) 


\section{APPENDIX A}

PSID Sibling Correlations for Various Measures of Net Worth: 1983-2001 Waves (Number of Person-Years, Number of Individuals, and Number of Families Below)

\begin{tabular}{lc}
\hline Natural log of the absolute value of net worth (minus & 0.265 \\
home equity) with 0 net worth set to 1.1, times the sign of & 5,041 \\
the value of net worth. & 1,767 \\
& 788 \\
\hline Natural log of the absolute value of net worth (minus & 0.267 \\
home equity) with 0 net worth set to -1.1, times the sign of & 5,041 \\
the value of net worth. & 1,767 \\
& 788 \\
\hline Natural log of the absolute value of net worth with main & 0.305 \\
home equity included, and with 0 net worth set to 1.1, & 5,041 \\
times the sign of the value of net worth. & 1,767 \\
& 788 \\
\hline Natural log of the absolute value of net worth with main & 0.306 \\
home equity included, and with 0 net worth set to -1.1, & 5,041 \\
times the sign of the value of net worth. & 1,767 \\
\end{tabular}




\section{Appendix B: Addressing Serial Correlation}

For the occupational prestige, earnings, income, and socioeconomic status measures that may demonstrate autocorrelative processes-leading to an underestimation of sibling resemblance-we also estimate family effects for the residuals adjusted for first-order serial correlation. To relax the assumption of no serial correlation in income or wealth, we follow Solon et al. (1991) and posit the following autoregressive process for income/wealth in a given year for person $\mathrm{j}$ :

$$
v_{i j t}=\lambda v_{i j, t-1}+z_{i j t}
$$

where $\mathrm{z}$ is a nonautocorrelated residual and the variance of $v_{i j t}$ can now be expressed as:

$$
\sigma_{v}^{2}=\sigma_{z}^{2} /\left(1-\lambda^{2}\right)
$$

If we substitute this equation back into our original variance decomposition (equation 4) we get the following:

$$
\varepsilon_{i j t}-\hat{\lambda} \varepsilon_{i j, t-1}=(1-\lambda) a_{i}+(1-\lambda) u_{i j}+z_{i j t}
$$

The variance of this estimate can then be decomposed in the same way as the simpler model (equation 4) was, into: $(1-\lambda) \sigma_{a}^{2}+(1-\lambda) \sigma_{u}^{2}+\sigma_{z}^{2}$. To estimate $\lambda$, we follow Solon et al.'s (1991) lead and regress the difference in residuals at time t and t-1 by the difference between residuals at $\mathrm{t}-1$ and $\mathrm{t}-2$. The resulting regression coefficient represents a parameter estimate of the first-order serial correlation which can be expressed as $(\lambda-1) / 2$. Solving for $\lambda$ gives us a predicted value for $\lambda$ of $\hat{\lambda}=1+2 r$.

Since wealth is measured intermittently in the PSID, we were not able to correct for negative first-order serial correlation in the data. Now that the PSID documents 
wealth during every wave (even if those waves are now every other year) future researchers will be able to estimate a $\lambda$ value for net worth and adjust the sibling correlation upward. Accounting for autocorrelation changes occupational prestige from .418 to .429 . Accounting for autocorrelation changes the correlation in earnings from .376 to .341 and the correlation in income and class position I from .458 to .270 and .612 to .451 , respectively. 